\title{
ANTICIPATING ROADWAY EXPANSION AND TOLLING IMPACTS: A TOOLKIT FOR ABSTRACTED NETWORKS
}

\author{
Daniel J. Fagnant \\ Graduate Student Researcher \\ The University of Texas at Austin - 6.9, E. Cockrell Jr. Hall \\ Austin, TX 78712-1076 danfagnant@ hotmail.com \\ Kara M. Kockelman \\ (Corresponding author) \\ Professor and William J. Murray Jr. Fellow \\ Department of Civil, Architectural and Environmental Engineering \\ The University of Texas at Austin - 6.9 E. Cockrell Jr. Hall Austin, \\ TX 78712-1076 \\ kkockelm@mail.utexas.edu \\ Phone: 512-471-0210 \& FAX: 512-475-8744 \\ Chi Xie \\ Research Fellow \\ The University of Texas at Austin - 6.9, E. Cockrell Jr. Hall \\ Austin, TX 78712-1076 chi.xie@ mail.utexas.edu
}

\section{The following is a pre-print and the final publication can be found in the Journal and Urban Planning of Development, Volume 140 (4), 2014.}

Key Words: Forecasting, travel behavior modeling, transportation planning, project evaluation

\begin{abstract}
Transportation investments are nearing $\$ 1,000$ per capita annually in the U.S., and the Highway Trust Fund has been depleted. Such significant investments and budget-constrained contexts demand careful decision-making and thoughtful cost-benefit analysis. A toolkit has been developed for comprehensive assessment of network expansion and pricing projects with only project expenditures, link attributes, and traffic counts as required inputs. The toolkit uses a selfcontained travel demand model to predict future and alternative scenario traffic volumes, speeds, crash counts, emissions and toll revenues, while providing project-summary measures, including net present value and benefit/cost ratios. The toolkit seeks to provide early assessment of major projects along abstracted networks, using hundreds of coded links (rather than thousands), providing results in a matter of minutes (rather than days). This paper describes the model and develops two case study sites, each with several alternative scenarios. The first examines capacity expansion projects along a highly congested link on the periphery of Austin, Texas, while the second focuses on strategies to reduce traffic in central Austin (through tolling and
\end{abstract}


capacity reduction projects). Toolkit results show which projects merit further consideration by summarizing and monetizing impacts across scenarios.

\section{INTRODUCTION}

The Highway Trust Fund's surplus has disappeared, and funding for transportation projects has become increasingly constrained. Revenue streams from gasoline taxes have fallen, as federal gas taxes and light-duty-vehicle fuel economies have remained constant (at 18.4 cents per gallon [Jackson 2006] and 20 miles per gallon [EPA 2010], respectively, since 1997). At the same time, transportation needs are increasing. Between 1984 and 2009 the United States population grew by 30\% (US Census Bureau 2000 and 2009) while VMT rose 71\% (FHWA 2009).

These changes have resulted in federal legislation (SAFETEA-LU) calling for transportation agencies to conduct comprehensive project evaluation before funding large scale projects (FHWA 2010). The U.S. Governmental Accountability Office (GAO) found that "the largest highway, transit and safety grant programs distribute funds through formulas that are typically not linked to performance and, in many cases, have only an indirect relationship to needs" (2008 p. 31). Thirty-four surveyed state DOTs responded that political support and public opinion are very important when making funding decisions, compared to only 8 that expressed the same level of importance for benefit-cost $(\mathrm{B} / \mathrm{C})$ ratios. The GAO notes that "Rigorous economic analysis, applied to benefit-cost studies, is a key tool for targeting investments" (2008 p. 37). In order to accomplish this goal, transportation agencies must develop and apply tools to predict project impacts.

This paper details one such toolkit for the analysis of major highway capacity expansion and tolling project applications. This new Project Evaluation Toolkit quickly assesses changes in travel patterns, traveler welfare, travel time reliability, vehicle crashes, emissions, fuel use and tolling revenues across multiple scenarios in order to quantitatively evaluate project alternatives. The Toolkit enables agency staff and decision makers to rigorously compare each alternative scenario and pursue projects that are likely to provide the best outcomes per dollar invested.

\section{Review of Literature}

Currently, several tools exist for highway project evaluation. Most of these are either limited in scope to single corridor analysis (such as HERS-ST or Cal-BC) or very detailed (such as regional transportation planning models). The Project Evaluation Toolkit described in this paper takes a middle road, using an abstracted network of as many links as analysts wish to include for assessing broad travel pattern changes without the extensive detail required for a fully developed travel demand model. Furthermore, while many existing toolkits analyze certain impacts, none evaluates as many output measures (such as travel time reliability and internal rates of return across random inputs of parameter simulations).

The FHWA's Highway Economic Requirements System - State Version (HERS-ST) evaluates project impacts based on pavement quality, operating costs, safety costs, travel time changes and emissions. Emissions of VOC, NOx, SOx, and PM2.5 are estimated based on vehicle speeds (FHWA 2005). HERS-ST estimates changes in travel demand using elasticities (i.e., the 
"rebound effect", or latent demand effects, as network travel times fall). HERS-ST estimates simple link-level demand (ignoring link connections) but does not contain an embedded travel demand model to account for shifting traffic patterns on parallel or alternate routes between origin-destination pairs and is therefore more suited for corridor analysis, rather than network analysis.

In association with Cambridge Systematics, System Metrics Group developed the California Life-Cycle Benefit/Cost Analysis Model (Cal-B/C) for the California Department of Transportation (2009). This spreadsheet-based toolkit estimates changes in crashes, emissions, travel time savings and operating costs. $\mathrm{Cal}-\mathrm{B} / \mathrm{C}$ requires users to input before and after traffic link volumes, thus requiring additional analysis outside the tool.

Many transportation planning models are custom developed for metropolitan planning organizations (MPOs). Individual models vary widely in methodology and capabilities, from detailed traveler activity based models, to simpler zonal production-attraction gravity models with logit models or fixed shares for mode and time of day (TOD) choices. Such models require many detailed inputs and often rely on trip generation information obtained from area demographics. They also can contain tens of thousands of highway links and take significant time and processing power to run a single scenario alternative. While they seek to provide robust and defensible traffic volume estimates, they do not directly offer key summary measures for project analysis, including crash prediction and travel time reliability. Of course, they can be integrated with other toolkits, such as the Environmental Protection Agency's (EPA) new MOVES to assess vehicle emissions.

Other project analysis toolkits include EPA's COMMUTER (Carlson et. al 2005), which analyzes emissions impacts from commuter related strategies (e.g., carpools, transit, bicycle programs, etc.) but does not use any direct network information; DeCorla-Souza's IMPACTS (1999), which focuses on corridor capacity expansion, tolling, transit and bicycle projects to estimate congestion, emissions ( $\mathrm{HC}, \mathrm{CO}$ and $\mathrm{NOx}$ ), fuel consumption and vehicle crash impacts; and FHWA's STEAM (Cambridge Systematics 2000), which uses a four-step planning model to anticipate changes in congestion, accessibility, crashes, and emissions. STEAM relies on a userspecified trip table, as well as zonal production and attraction information, as key inputs.

\section{TOOLKIT DESCRIPTION}

The new Project Evaluation Toolkit relies on user-entered base-case and alternative-scenario transportation networks with link-specified traffic volumes (AADT). It uses this information to estimate future year traffic volumes based on network changes and base-case node-pair travel demand growth rates. Impacts are then assessed for traveler welfare (based on cost and travel time changes, using the rule of half ( $\mathrm{RoH})$ and/or logsum differences), travel time reliability, crashes, emissions, fuel use and tolling revenues. The Toolkit uses project cost and impact results to produce economic summary measures to help transportation planners and policy makers prioritize projects. All impacts are interpolated between the initial year and the designlife year (using linear or exponential expressions). Finally, the Toolkit has sensitivity analysis capabilities that allow users to examine the impacts of uncertain parameter inputs (e.g., values of time and traffic growth rates), in order to generate ranges of potential scenario outcomes. 


\section{Travel Demand Modeling Process}

The fully integrated travel demand model is a key Toolkit component. This model strives to closely mimic full-network demand estimation results across different roadway facilities, times of day, and changed network conditions, while reducing computing times, data demands, and staff expertise requirements. The effort and input required to run such abstracted models are much lower than for the full-network counterpart.

The Toolkit's travel demand model uses five major steps to assign traffic for alternative scenarios and future years. These produce a base trip table estimate, elastic trip table estimates for each scenario, mode split and time of day estimates, and link-based traffic assignments (for each traveler class modeled). Once the traffic assignment process is complete, the model checks for convergence (using traffic flow stability as described later) and loops back to the elastic trip table estimation process if convergence has not been reached, as shown in Figure 1.

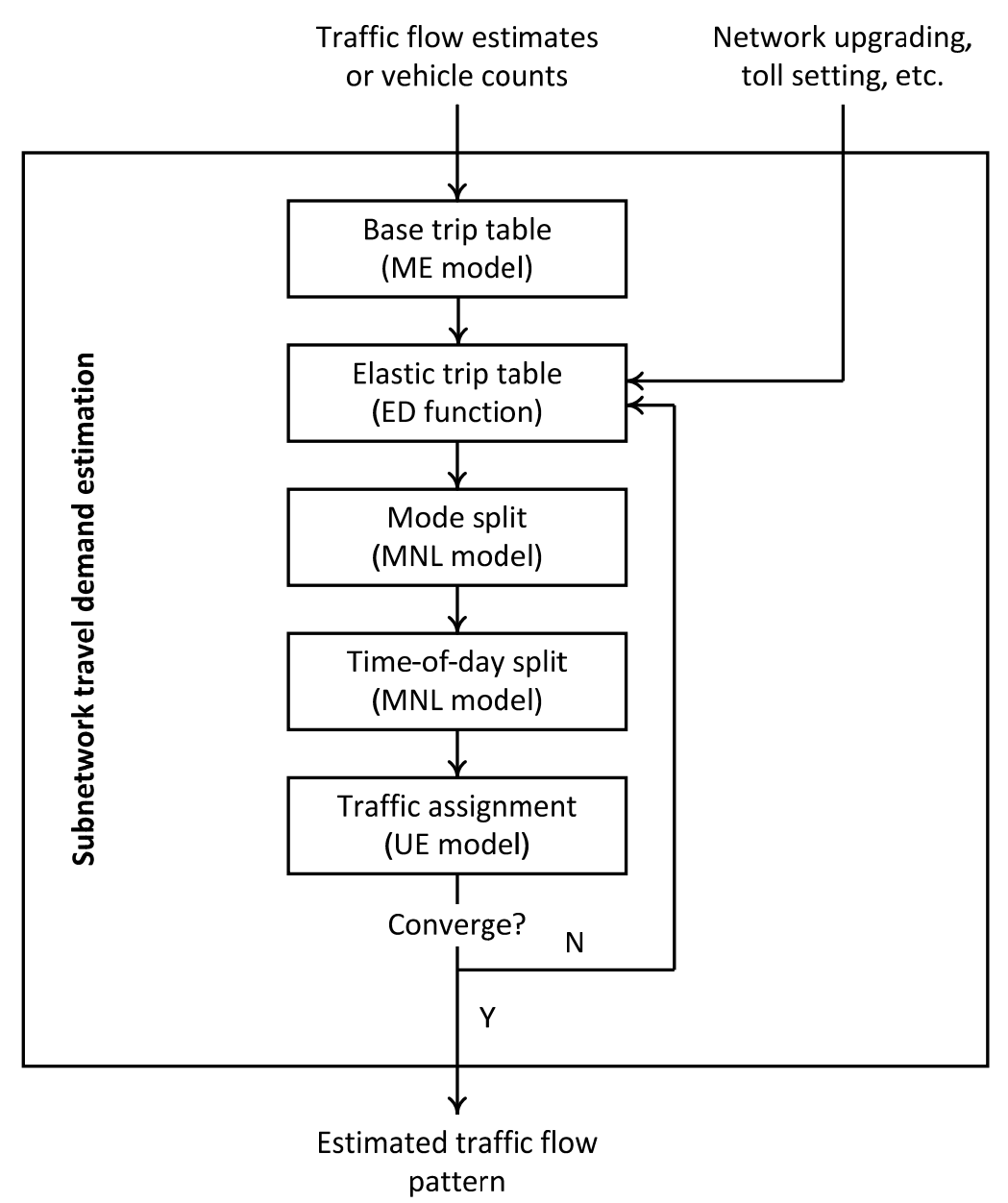

Figure 1: The Abstracted Network Travel Demand Modeling Process

The first step's estimate of the origin-destination (O-D) trip table is based on link flow rates from field measurements (e.g., the Highway Performance Monitoring System's AADT values) or 
other sources (such as a previous travel demand model run). This is performed using a constrained maximum-entropy (ME) process which approximates travel demand patterns as described in Xie et al. (2010). Future-year travel demands between each O-D pair for the basecase (no-build) option are based on a user-assumed growth rate (e.g., 1\% per year). The second step uses an elastic demand (ED) function to estimate cost-dependent O-D trip rates for all other scenarios, by pivoting off of the base-case trip rates using an assumed demand elasticity for each time of day (e.g., -0.5 during the AM peak period). The third step, mode split, uses an incremental multinomial logit (MNL) model (Ben Akiva and Lerman 1985) to distribute the O-D trip rates (as developed in the second step) into different transportation modes, such as drivealone, shared-ride modes, transit, and non-motorized modes. The fourth step also uses an incremental MNL model to produce trip tables by time of day for each transportation mode. The fifth step assigns these various trip tables (by vehicle type, traveler class, travel mode, and time of day) to the abstracted/coded network under the user-equilibrium principle. It should be noted here that the last four steps form a supply-demand interaction loop and are conducted iteratively, so that computations of trip shares in the second, third and fourth steps are consistent with the time-and-cost outputs of the fifth step. In other words, supply-demand interactions are treated with "full feedback" (rather than just equilibrating travel times and costs in the fifth step, across routes, leaving trip tables fixed).

While the first step involves a one-time, trip table estimation event for the base-case condition, all other steps are part of the iterative process with a feedback mechanism, to ensure that flows and costs are in equilibrium, between different times of day, across modes, and across routes. The feedback process iterates over the last four steps until the consistency between traffic flows and travel costs are reached (such that the gap between successive flow estimates is low).

The major structural difference between the Toolkit's travel demand modeling process and the traditional four-step process lies in trip generation and distribution. The Toolkit generates the OD trip table entirely based on observed traffic counts, while the traditional process estimates trip productions and attractions from land use and socioeconomic data. Kockelman et al.'s (2010) final project report and toolkit documentation provide further details on the Toolkit's travel demand model processes and parameter estimates.

\section{Traveler Welfare Estimates}

The demand model estimates traveler welfare benefits of each project scenario (vs. the no-build base case). These changes in traveler welfare are a function of travel times (and thus link speeds and traffic volumes) and direct user costs (such as fuel and tolls). Traveler welfare estimates are evaluated by O-D pair, by necessity ${ }^{1}$ : When demand is elastic (i.e., travelers can choose different times of day, modes, and destinations), the economic value of complete trips cannot be captured at the link level.

The Toolkit estimates traveler welfare using the RoH reflecting benefits to new travelers as well existing travelers between each O-D pair. As shown in Figure 2, the benefit to users equals the shaded areas. The $\mathrm{RoH}$ assumes a linear demand function applies estimation of Figure 2's area

\footnotetext{
${ }^{1}$ The Toolkit can also assume a fixed trip table between scenarios, if the analyst wishes to avoid uncertainty in forecasting latent demand for travel and other behavioral responses to network modifications.
} 
1, for travel between each O-D pair. The Toolkit also assumes multiple values of time, so each user group will experience different benefits (or costs) between each O-D pair. These impacts are summed over all O-D pairs, all traveler types, all modes and all TODs, to properly reflect cost and benefit changes experienced by all system users.

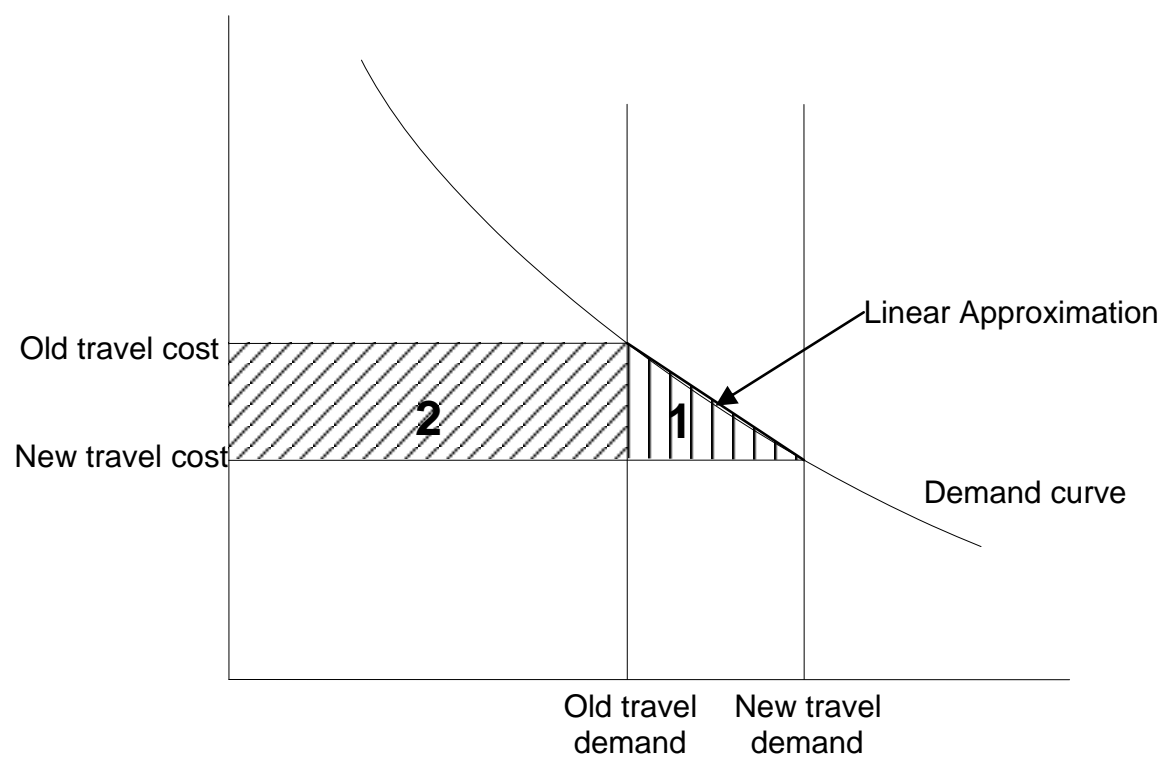

Figure 2. Changes in Consumer Surplus (in Shaded Areas) as Travel Price Falls (and Demand Rises)

\section{Reliability Estimates}

The Toolkit defines unreliability as the standard deviation in (link-level) travel times, so that reliability may be summed over all links, similar to travel times for route choices. Travel time deviations are estimated using a relationship calibrated between freeway volume-capacity ratios and travel time variances using traffic data provided by Cambridge Systematics, and obtained from two- to five-mile long freeway segments in Atlanta, Los Angeles, Seattle and Minneapolis (Margiotta, 2009). The relationship is similar to a shifted version of the Bureau of Public Roads (BPR) link performance function, as follows:

$$
r_{a, S D}=\sqrt{r_{a, V A R}^{0}\left(1+\sigma\left(\gamma+\frac{v_{a}}{c_{a}}\right)^{\tau}\right)}
$$

where $r_{a, V A R}^{0}$ is the free-flow travel time variance of link $a$, and $\sigma, \gamma$ and $\tau$ are function parameters. Ordinary least squares regression resulted in the following parameter estimates: $r_{a, V A R}^{0}=0.001, \sigma=2.3, \gamma=0.7$, and $\tau=8.4$. More details can be found in the Toolkit's documentation (Kockelman et al. 2010). 
The Toolkit multiplies each link's travel time unreliability by each user's value of reliability ${ }^{2}$ and sums over all links to determine the total system reliability costs.

\section{Crash Estimates}

Crashes are predicted using safety performance functions (SPFs) derived from Bonneson and Pratt's Road Safety Design Workbook (2009). These SPFs allow users to pivot off existing crash rates and crash counts to estimate future numbers of fatal, injurious $(\mathrm{F}+\mathrm{I})$ and property damage only crashes on each link in the system. Key factors are link functional classification, AADT and number of lanes. Local land use type, median type, and intersection control also have important safety impacts along arterials, while entrance and exit ramp frequencies are important for freeways. Segment (link) crashes are estimated for all Toolkit-coded roadway types, and intersection crashes are estimated for arterials and rural roads.

The Toolkit default is to include the monetary impacts of motor vehicle crashes when assessing each project's Net Present Value (NPV), B/C ratio, Internal Rate of Return (IRR), and Payback Period (PP). Default crash costs were obtained from the National Highway Traffic Safety Administration's Economic Impacts of Motor Vehicle Crashes 2000 (Blincoe et al. 2002), with a conversion to the USDOT's KABCO severity scale (and inflation to year 2010 costs). These values include market costs, such as lost productivity, medical services, travel delay and property damage, but they do not include non-market factors, such as the value of life, pain and suffering and values based on "willingness-to-pay" in order to avoid collisions.

\section{Emissions Estimates}

The Toolkit predicts emissions rates and totals using the U.S. Environmental Protection Agency's MOBILE 6.2 model's rates. The Toolkit's extensive (1.37-million row) lookup tables provide grams per mile for 13 emissions species. These are the standard hydrocarbons (HC), carbon monoxide $(\mathrm{CO})$, oxides of nitrogen $(\mathrm{NOx})$, carbon dioxide $\left(\mathrm{CO}_{2}\right)$, particulate matter $<$ $2.5 \mu \mathrm{m}\left(\mathrm{PM}_{2.5}\right)$, particulate matter $<10 \mu \mathrm{m}\left(\mathrm{PM}_{10}\right)$, and sulfur dioxide $\left(\mathrm{SO}_{2}\right)$, along with the following mobile-source air toxics (MSATs): ammonia $\left(\mathrm{NH}_{3}\right)$, benzene $(\mathrm{BENZ})$, butadiene (BUTA), formaldehyde (FORM), acetaldehyde (ACET), and acrolein (ACRO). While many MSATS are not yet regulated, they are carcinogenic and thus of interest to the public and its policy makers (Health Effects Institute 2007).

Emissions rates depend on facility type (freeway, arterial, local road, or ramp), vehicle speed (14 speed categories - from $2.5 \mathrm{mph}$ and slower to $65 \mathrm{mph}$ and faster), temperature range (four temperature ranges, with 30 degrees at the low end and 105 at the high end), year of analysis (based on analysis year closest to 2010,2015,2020, or 2025, and impacting vehicle ages [and thus rates]), vehicle type (28 types), and vehicle age (6 age categories in 5 year increments). The Toolkit estimates the number of light and heavy duty vehicles on each link and their respective speeds. Sub-categories of light and heavy vehicles are then extrapolated from overall vehicle fleet distribution tables. Emissions rate estimates are provided for normal, exhaust generation of

\footnotetext{
${ }^{2}$ Brownstone and Small (2005) estimated the value of reliability (VOR), as measured in $\$ / \mathrm{hr}$ of travel time standard deviation, to be roughly 95 to $145 \%$ of the corresponding VOTT along freeways SR-95 and I- 15 in the Los Angeles area. For this reason, the Toolkit default is to assume that each user class' VOR equals its VOTT.
} 
all emissions types. Evaporative emissions are also estimated for $\mathrm{HC}$ and BENZ, as are $\mathrm{PM}_{2.5}$ and $\mathrm{PM}_{10}$ from brake wear and tear.

MOBILE6.2 assumes fixed CO2 emissions rates (and essentially constant PM emissions rates) with speed, which is generally found to be unrealistic. Fuel use and $\mathrm{CO} 2$ values across different speeds were modified based on fuel economies developed under work by West et al. (1997), as presented in Davis and Diegel (2007). Lower speeds thus significantly impact $\mathrm{CO}_{2}$ and most other species, though not $\mathrm{PM}$ or $\mathrm{NH}_{3}$ (which remains unintuitive). Various emissions rates begin to rise slightly for certain species above $40 \mathrm{mph}$ but MOBILE6.2 rates terminate at $65 \mathrm{mph}$. Figure 3 illustrates per-mile emission rates with respect to vehicle speed on a freeway facility with 10\% heavy vehicles at 80 degrees Fahrenheit for $\mathrm{HC}, \mathrm{CO}$ and NOx.

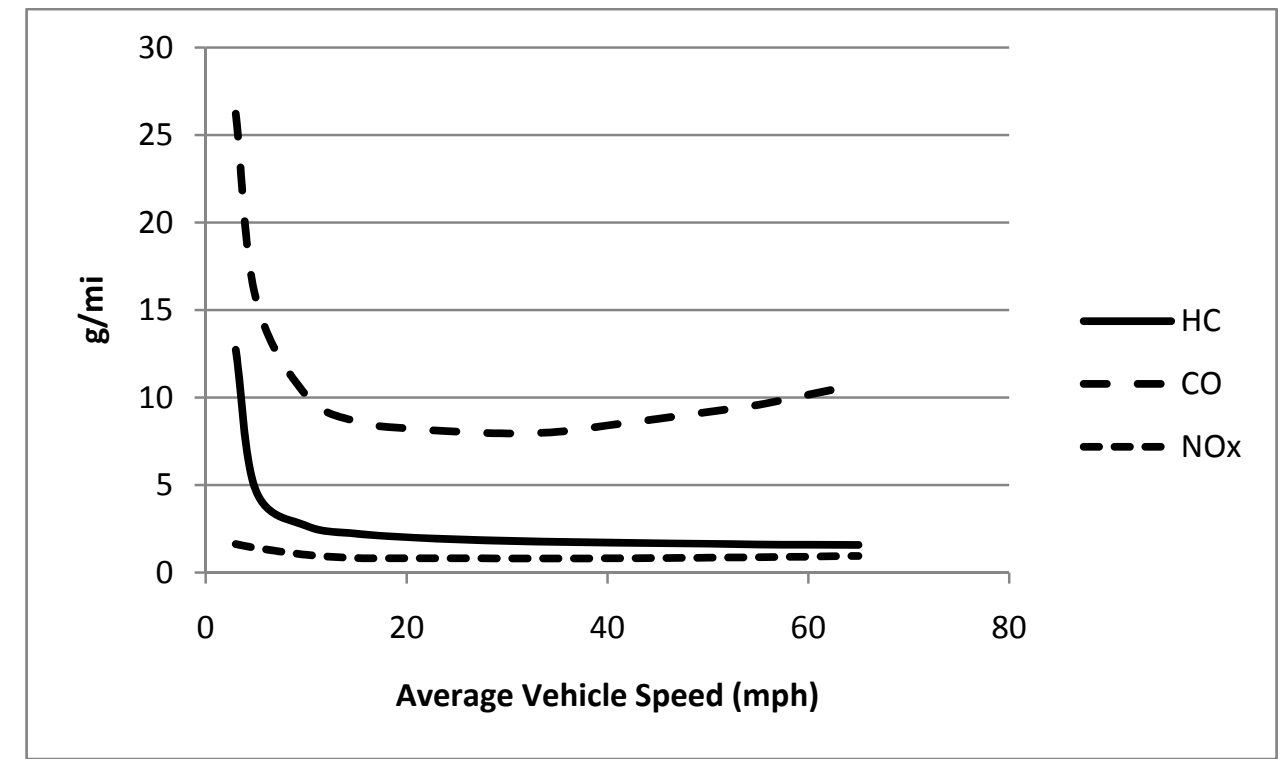

Figure 3: Freeway Emission Rates (2010, 10\% HDV, 80 F)

Toolkit defaults do not monetize emissions, though McCubbin and Delucchi (1996) provide US estimates and Mailbach et al. (2008) present European estimates of emission costs for certain species based on health impacts. These range from $\$ 2900-\$ 5800$ per ton of HC, $\$ 70-\$ 140$ per ton of CO, \$620-\$7600 per ton of NOx, $\$ 620-\$ 18,000$ per ton of $\mathrm{SO}_{2}$ and $\$ 4500-\$ 830,000$ per ton of $\mathrm{PM}_{2.5}$ (all 2010 \$US), depending on area density, country and study.

\section{Summary Evaluation Measures}

The Toolkit produces four summary measures (NPV, B/C, PP, and IRR, as noted earlier) for each project scenario, over the project lifetime. All measures require a base-case (typically nobuild) point of reference to determine project impacts in terms of changes in traveler welfare and other benefits having monetary equivalents. NPV is determined with project costs as absolute values (not in relation to the base-case scenario), while other summary measure costs are in relation to the base-case scenario.

NPV is the project's worth over the entire design life (e.g., 20 to 30 years) in present dollars (measured from the initial build year). The $\mathrm{B} / \mathrm{C}$ ratio is the sum of discounted (initial-year) 
benefits (relative to the base-case/no-build scenario) divided by the sum of discounted project costs over the entire project life. All project impacts are assumed to be benefits, and all changes to agency budgets are assumed to be costs. The PP is the point in time at which of the NPV of annual benefits first equals the NPV of all project costs, relative to the base-case scenario. The project's IRR determines the discount rate at which the sum of discounted costs equals the sum of discounted benefits (at their present-year worth) (Newnan and Lavelle 1998). If the B/C ratio is negative (i.e., greater disbenefits than benefits), the toolkit will report that the scenario's IRR is negative (but give no specifics).

Traveler welfare (emphasizing travel time and operating costs) is always included in these summary measures. Travel time reliability, motor vehicle crash costs, and air pollutant costs may be monetized and included in the summary economic measures at the discretion of the analyst. The Toolkit default monetizes market or economic components of crash costs only (including property damage, medical costs and lost productivity). The default does not monetize emissions costs, simply because these vary with exposure to population and remain rather uncertain and undocumented by the US EPA. However, the Toolkit's documentation provides ranges of potential valuations users can input if they elect to monetize these. Fuel consumption is not included in the summary measures because it is already accounted for in the operating costs component of traveler welfare valuations. Toll revenues are also not included because their direct impact should be neutralized by the transfer of traveler monies to tolling agencies. In other words, this cost to travelers is an equal dollar benefit to road authorities, excluding maintenance and overhead. However, the user-friendly MS Excel spreadsheets of the Toolkit (which serve as the graphical user interface) provide all these values.

\section{AUSTIN CASE STUDIES}

Two major case studies were conducted in Austin to test the Toolkit's capabilities. The first focuses on a 5.2 mile stretch of US Route 290 between US Route 183 and State Highway 130. US Route 290 is a major East-West corridor on the edge of Austin in a developing area of the city, about 7 miles northeast of Austin's downtown and capitol building. Travel demand currently matches or exceeds roadway capacity along this four-lane arterial during the mid-day and PM peak periods. Three alternative scenarios were investigated, including a grade-separated freeway upgrade (keeping the same number of lanes), a grade-separated tollway (keeping the same number of lanes and tolled at $\$ 1$ or just under $\$ 0.20$ per mile), and an added lane in each direction.

The second major case study focuses on strategies to limit travel demand on an 8-lane 4.9 mile stretch of Interstate Highway I-35 between US Route 183 and $15^{\text {th }}$ Street. I-35 is a major U.S. trade corridor and the backbone of Austin's congested network, running north-south through the eastern edge of Austin's downtown, with over 100,000 AADT in each direction along the modified segments. Three alternative scenarios were examined in this case study; the first two attempt to limit travel demand by introducing either a $\$ 1$ or a $\$ 2$ toll (just under $\$ 0.20$ and $\$ 0.40$ per mile, respectively), and the third attempts to limit capacity by removing a travel lane in either direction (to match the 6-lane sections that lie just outside the 4.9-mile stretch). 


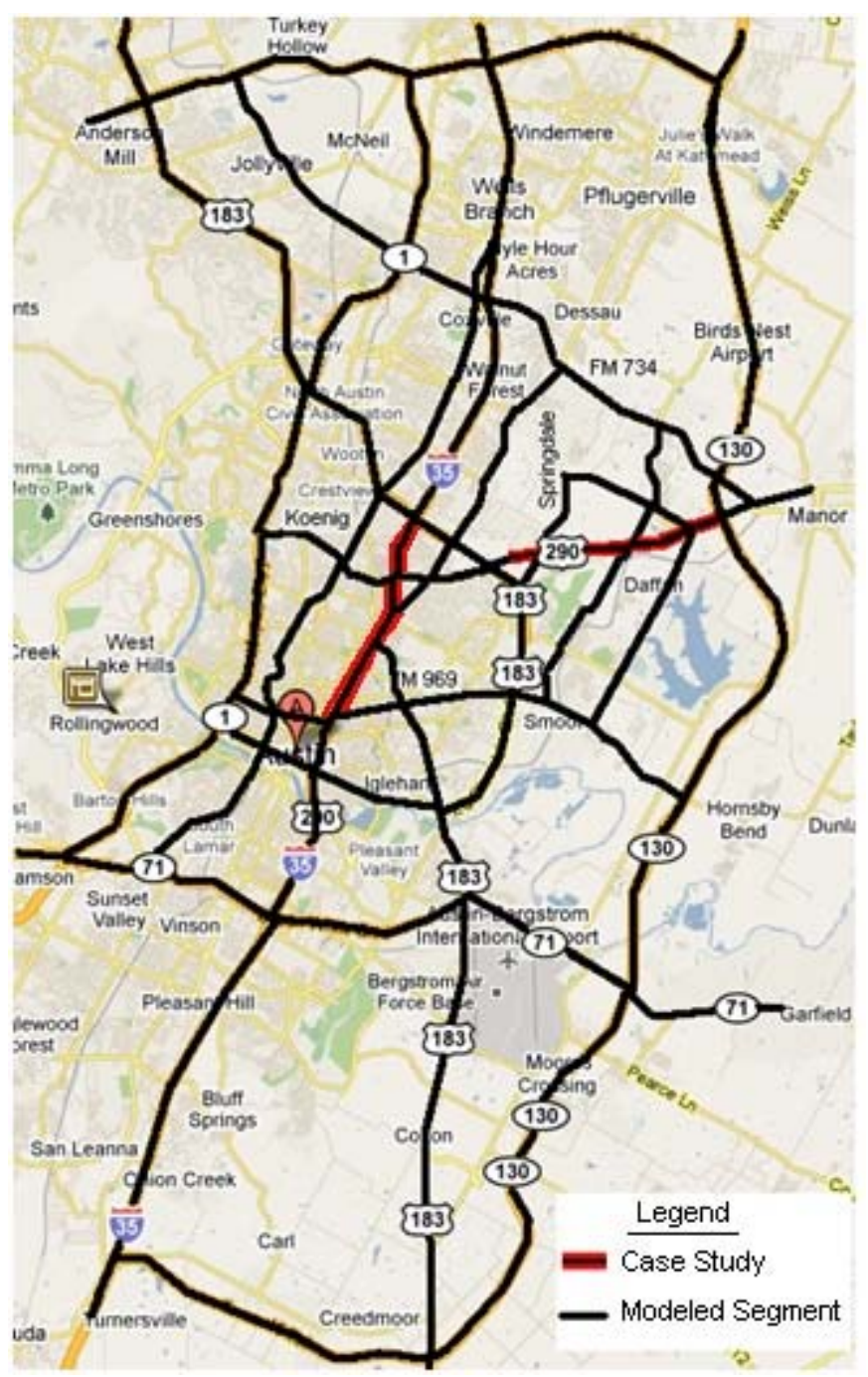

Figure 4: Case Study Area Locations

To model both contexts, an abstracted roadway network for the region was created as shown in Figure 4. It includes 194 freeway and arterial links and 62 nodes, capturing approximately 70\% of all Austin area VMT. Link capacities were obtained from the Capital Area Metropolitan Planning Organization's (CAMPO's) regional travel demand model, and traffic link volumes were obtained from the Texas Department of Transportation's (TxDOT's) most recent 2008 traffic counts (CAMPO 2009). An annually compounded 1\% growth rate in travel demand between all O-D pairs was assumed, along with a 5\% annual discount rate. This latter value is lower than the 7\% required by the Office of Management and Budget (OMB) for federal projects, but is on the high end of the 3 to $5 \%$ discount rates typically used for state transportation projects, as reported by the FHWA (2007). Summer temperatures were assumed to average 80 degrees and winter temperatures 50 degrees Fahrenheit (impacting emissions rates). Fatal and injury ( $\mathrm{F}+\mathrm{I})$ crashes as a share of total crashes was assumed to mirror Texas' statewide statistics for urban areas (TxDOT 2009) (so 1.2\% of all F+I crashes were assumed to be fatalities. 
Four user classes were assumed, with AADT input shares in the base-case initial year as follows: $10 \%$ of total traffic on each link as commercial trucks with a $\$ 50$ per hour VOTT, 10\% workrelated travelers with a $\$ 30$ per hour VOTT, $20 \%$ at $\$ 10$ per hour VOTT, and $60 \%$ at $\$ 5$ per hour VOTT. Those seeking further details can refer to Kockelman et al.'s (2010) report. All case studies represent hypothetical uses for the Toolkit, and do not reflect actual planned projects.

\section{Capacity Expansion (Case Study 1)}

The US Route 290 case study enjoys an existing/base-case corridor capacity that varies between 1360 vehicles per hour (vph) and $1720 \mathrm{vph}$. This was expanded to a uniform capacity of 3820 vph in the tolled and non-tolled grade-separation alternatives and to a uniform capacity of 2040 vph in the lane-add scenario. Project costs were estimated at $\$ 71.8$ million for Alternative 1 (non-tolled grade-separated freeway), \$72.9 million for Alternative 2 (grade-separated tollway), and \$25.8 million for Alternative 3 (arterial with lane additions). Each scenario was assumed to require increased annual funding for facility maintenance and operations, at $\$ 184$ thousand per year for the Alternative 1, $\$ 384$ thousand per year for Alternative 2 (not accounting for toll collection offsets), and $\$ 40$ thousand per year for Alternative 3. A year 10 (mid-life) $\$ 30$ million pavement reconstruction project was also required for Alternative 3 (since the main facility remained, and would need rehabilitation before 20 years passed). Project construction, road maintenance and reconstruction cost estimates were obtained from the Victoria Transport Policy Institute (2009).

Alternative 3 appears as the preferred alternative based on B/C, IRR and PP measures, while Alternative 1 is preferred from a NPV perspective, as shown in Table 1. This sort of shift in rankings is common in practice, as "bigger" projects generally enjoy higher NPVs (Alternative 1) but potentially lower $B / C$ ratios and IRRs. Here, all IRRs and $B / C$ ratios are high (while the Do-Nothing base case is costly), suggesting all alternatives make sense, even though reliability and emissions benefits are not yet included (though the former are sizable), and crash benefits are only monetary in nature (but remain slight when non-monetary benefits are added).

\begin{tabular}{|l|r|r|r|r|}
\cline { 2 - 5 } \multicolumn{1}{c|}{} & \multicolumn{1}{c|}{$\begin{array}{c}\text { Base-Case: } \\
\text { No Build }\end{array}$} & $\begin{array}{c}\text { Alternative 1: } \\
\text { Grade Sep. } \\
\text { Freeway }\end{array}$ & $\begin{array}{c}\text { Alternative 2: } \\
\text { Grade Sep. } \\
\text { Tollway }\end{array}$ & $\begin{array}{c}\text { Alternative 3: } \\
\text { Extra Lanes } \\
\text { (Arterial) }\end{array}$ \\
\hline Net Present Value & $-\$ 18 \mathrm{M}$ & $\$ 134 \mathrm{M}$ & $\$ 109$ & $\$ 117$ \\
\hline Internal Rate of Return & N/A & $26 \%$ & $22 \%$ & $70 \%$ \\
\hline Benefit / Cost Ratio & N/A & 3.86 & 3.24 & 6.38 \\
\hline Payback Period (yrs) & N/A & 4.9 & 6.0 & 1.6 \\
\hline
\end{tabular}

Table 1: Economic Summary Measures of Case Study 1's Project Alternatives

Traveler welfare and system reliability benefits, are striking, in terms of impact magnitudes. Annual traveler welfare benefits of Alternative 1 range from $\$ 10$ (initial year) to $\$ 14$ million (design year) - similar to other alternatives, while travel time reliability benefits varied from $\$ 18$ to $\$ 281$ million, crashes from $\$ 0.4$ to $\$ 4$ million (\$0.9 to $\$ 9$ million when using willingness to pay measures, as reported by NSC [2010]), and $\mathrm{HC}, \mathrm{CO}, \mathrm{NOx}, \mathrm{SO}_{2}$ and $\mathrm{PM}_{2.5}$ from $\$ 0.5$ to $\$ 2$ 
million (total) when using McCubbin and Delucchi's (1996) pollutant cost estimates, inflated to 2010 dollars.

Over the entire 20-year evaluation period, the Toolkit also estimates that the Alternative 1 results in the fewest fatal and injury crashes. This scenario resulted in $1481 \mathrm{~F}+\mathrm{I}$ fewer crashes than the base-case scenario over 20 years. This compares to the 39.4 thousand total system crashes in the base case scenario and thus amounts to a $3.76 \%$ reduction in total predicted crashes. Similar reductions are estimated for Alternative 2, and about one-third of these benefits under Alternative 3.

The Toolkit estimates that total system VMT fell just $0.11 \%, 0.05 \%$ and $0.01 \%$ in the initial year (from 5.57 billion annual VMT) and by $0.66 \%, 0.62 \%$ and $0.61 \%$ in the design year (from 6.85 billion) for Alternatives 1, 2 and 3, respectively. This VMT decrease, along with other changes, such as increased speeds, resulted in very slight emission reductions across almost all species in all scenarios. Traffic volumes and (flow-weighted) average speeds along the altered corridor increased from 20,900 AADT at $28 \mathrm{mph}$ in the base-case initial year to 23,300 AADT at $54 \mathrm{mph}$, 21,500 AADT at $54 \mathrm{mph}$ and 21,800 AADT at just $35 \mathrm{mph}$ under Alternatives 1, 2 and 3, respectively. In the design year traffic volumes and speeds along the corridor increased from an average of 25,600 AADT at $20 \mathrm{mph}$ (base case conditions) to an average of 29,900 AADT at 52 mph, 27,600 AADT at $52 \mathrm{mph}$ and 27,800 AADT at $26 \mathrm{mph}$ in Alternatives 1, 2 and 3, respectively.

\section{Travel Demand Management (Case Study 2)}

The second case study sought to reduce I-35 traffic levels by imposing tolls or reducing capacity. Alternative 1 imposed a $\$ 1$ toll (just over $\$ 0.20$ per mile), Alternative 2 imposed a $\$ 2$ toll (just over $\$ 0.40$ per mile), and Alternative 3 removed a travel lane in each direction (reducing capacity from $9200 \mathrm{vph}$ to $6900 \mathrm{vph}$ in each direction). It should be noted that the abstracted network (of 194 links) did not model I-35's frontage roads, and a more complete analysis that included these links may produce different results.

Though all scenarios attempted to reduce network VMT, results were mixed: slight VMT increases were estimated under both initial-year tolling alternatives and under Alternative 2's design year. While all alternative scenarios predicted travel reduction along I-35, the Toolkit's travel demand model predicted that many travelers would shift their routes rather than forego travel altogether. This is despite the model's accounting for the possibility of fewer total travelers through use of travel demand elasticities (which vary between -0.5 and -0.85 , depending on time of day ${ }^{3}$. Table 2 shows the Toolkit's estimated changes in the codednetwork's VMT. The 'Surrounding Links' row listed in Table 2 reflects VMT changes along the 24 links closest to the impacted I-35 project area. These links represent the most likely alternative routes that travelers could take instead of I-35, while still reaching the same destination.

\footnotetext{
${ }^{3}$ Period-dependent elasticity values were estimated using millions of predicted changes in flow rates between Austin's 1,074 zones from a few network upgrade scenarios (Lemp and Kockelman 2009)
} 


\begin{tabular}{|l|ccc|ccc|}
\cline { 2 - 7 } \multicolumn{1}{c|}{} & \multicolumn{3}{c|}{ Initial Year } & \multicolumn{3}{c|}{ Design Year } \\
\cline { 2 - 7 } \multicolumn{1}{c|}{} & Alt 1 & Alt 2 & Alt 3 & Alt 1 & Alt 2 & Alt 3 \\
\hline System & $0.23 \%$ & $1.40 \%$ & $-0.01 \%$ & $-0.37 \%$ & $0.53 \%$ & $-0.46 \%$ \\
I-35 & $-9.0 \%$ & $-23.4 \%$ & $-1.3 \%$ & $-7.2 \%$ & $-19.1 \%$ & $-4.7 \%$ \\
Surrounding Links & $6.8 \%$ & $21.9 \%$ & $0.5 \%$ & $4.6 \%$ & $15.6 \%$ & $1.9 \%$ \\
\hline System & 12.8 & 78.0 & -0.72 & -25.2 & 36.4 & -31.6 \\
I-35 & -41.0 & -106.6 & -6.0 & -40.1 & -106.9 & -26.1 \\
Surrounding Links & 51.0 & 163.8 & 3.8 & 42.7 & 144.7 & 17.2 \\
\hline
\end{tabular}

Table 2: Toolkit-Estimated VMT Changes

(As a percentage of the base-case scenario and annual million VMT)

The most striking impacts are shown along one bypass route east of I-35. In Alternative 1's design year, Cameron Road's traffic volumes (between I-35 and US 183) rose by 54\%, accounting for an additional 16,000 vehicles on each of the four impacted links. Similarly, 20,000 additional vehicles were added to the US 183 links between $35^{\text {th }}$ Street and Cameron, increasing traffic on those links by $33 \%$. Additional changes in VMT could be attributed to longer distance trips. The cost increases on I-35 (either time or money) could cause some vehicles to take longer routes around it (thus increasing VMT) and other vehicles to forgo the trip altogether (thus decreasing VMT). Furthermore, a more complete analysis could be run, modeling I-35's frontage roads and other nearby alternative local routes. This may mitigate some of the system VMT increases that were shown in Alternate 3.

Traveler welfare impacts were uniformly positive, ranging from $\$ 5.7$ million (Alternative 2, initial year) to $\$ 15$ million (Alternative 1, design year). Crashes were predicted to increase in all scenarios, with Alternative 2 showing crash cost increases of up to over $\$ 13$ million in the initial and design years (crash costs rose by less than $\$ 3$ million per year in other scenarios). Reliability improved in Alternative 1 (\$8 million, initial year and \$68 million, design year), was mixed in Alternative 2 (-\$10 million, initial year and \$39 million, design year), and worsened in Alternative 3 (-\$24.5 million, initial and design years). All alternatives showed reductions in some pollutants and increases in others. For example, Alternative 1 results suggest a 2.2\% reduction in $\mathrm{HC}$ in the initial year, but a 3.2\% increase in CO. Overall, however, Alternative 1 resulted in the most significant air quality benefits (an average of $0 \%$ in the initial year and $1.1 \%$ in the design year), while Alternative 2 resulted in the worst air quality changes (increases of $1.5 \%$ in the initial year and $0.3 \%$ in the design year). Emissions and crash increases were attributable in part to changes in total VMT but also to shifting freeway traffic to arterials (where crash and emission rates are higher due to more stop-and-go behavior and conflicts, caused by signalized intersections and driveways).

\section{OPPORTUNITIES FOR TOOLKIT ENHANCEMENT}

While the Toolkit's application outcome yields a variety of reasonable results for very distinctive case studies, allowing for a great deal of user flexibility and meaningful outputs, the underlying models are, of course, imperfect. For example, trip growth rates presented are assigned a single 
constant between all O-D pairs. In reality, certain zones or nodes will have higher growth in activity (via land development and the like), so this limitation will be addressed in future installments (by allowing users to assign node-specific growth rates, averaging these between each origin and destination pair). Variable heavy truck distributions between O-D pairs and bus routes are also not yet accounted for in the Toolkit, and may be useful to add in some fashion.

The Toolkit estimates rely on constant shares for $\mathrm{F}+\mathrm{I}$ crash predictions, when in fact more severe crashes are likely along higher-speed facilities, everything else constant. Furthermore, traffic volumes on modeled links sometimes exceed those recommended by Bonneson and Pratt (2009) for using the SPFs that they developed.

Another Toolkit shortcoming is the process used to estimate travel time reliability. While reliability estimates are based on data collected from freeways with $\mathrm{V} / \mathrm{C}$ ratios between 0.4 and 1.1, the Toolkit allows traffic volumes to substantially exceed that range (reaching up to 2.83 on one link in the base-case, design year for Case Study 1). The Toolkit also presently caps standard deviation at $75 \%$ of travel time, in order to moderate overall estimates of reliability impacts (so they do not overpower travel time savings and other traveler welfare benefits). Yet very large reliability benefits (or disbenefits) still result on very congested links. Moreover, the model used to estimate reliability is based on freeway data, though the formula is applied to all coded links.

\section{CONCLUSIONS}

The Project Evaluation Toolkit described here was developed to provide transportation planners and policy makers with the ability to quickly predict and compare project impacts among a variety of alternative scenarios. This Toolkit's application complexity falls between a regional travel demand model and a stand-alone corridor analysis, while providing a host of new and increasingly critical outputs and costs. In this way, Toolkit users should be able to obtain a preliminary estimate of system-wide project impacts before conducting a more detailed analysis of demand patterns using a full-network demand model.

The Toolkit estimates changes in traveler welfare (accounting for changes in travel times and operating costs) as well as travel time reliability, crashes, emissions, fuel use and tolling revenues. It summarizes individual component impacts while providing economic summary measures. This allows users to comprehensively evaluate and compare scenario alternatives in a robust and consistent framework as outlined in the case studies described within this document.

Case study findings show that, when monetized, the Toolkit values reliability over all other measures. However, when reliability is excluded, as per the Toolkit's default, traveler welfare becomes the most important summary measure impact (excluding project costs). If monetized, crashes and emissions can still play a significant factor in overall project impacts, as they may account for up to a combined $44 \%$ of benefits, as was found in one scenario's design year impacts (using higher willingness to pay measures to avoid crashes. Furthermore, case study results show that attempts to reduce travel demand through congestion pricing or limiting capacity can have unintended results, such as shifting traffic to alternative routes that may be far less suited to handling the added traffic. 
While existing project evaluation tools provide transportation officials with a number of methods for project evaluation, the Toolkit described in this paper offers new outputs and applications not available in other tools. Transportation agencies adopting toolkits such as this will ideally help bring about a new era of project budgeting for optimal investment of public funds.

\section{ACKNOWLEDGEMENTS}

This paper and the work described herein would not have been possible without funding from the Texas Department of Transportation under research project \#0-6235, the work conducted by Dr. Tammy Thompson and Anne Hulsey to develop the MOBILE 6.2 emissions tables, extensive project support from Annette Perrone, and Toolkit review and feedback from Chris Williges, Dan Beagan, Ken Cervenka and many others. This paper and the Toolkit described herein reflect work in progress, as the Toolkit has not been formally accepted by the Texas Department of Transportation.

\section{REFERENCES}

Ben-Akiva, M. and S. Lerman. (1985). Discrete Choice Analysis: Theory and Application to Travel Demand. MIT Press, Cambridge, MA.

Blincoe, L.; Seay, A.; Zaloshnja, E; Miller, T.; Romano, E.; Luchter, S.; and Spicer, R. (2002) The Economic Impact of Motor Vehicle Crashes 2000. National Highway Traffic Safety Administration. Available Online at http://www.nhtsa.dot.gov/staticfiles/DOT/NHTSA/Communication\%20\&\%20Consumer\%20Inf ormation/Articles/Associated\%20Files/EconomicImpact2000.pdf.

Bonneson, James A. and Michael P. Pratt (2009) Road Safety Design Workbook. Texas Transportation Institute. Prepared for the Texas Department of Transportation. College Station, TX. Available Online at http://tti.tamu.edu/documents/0-4703-P2.pdf.

Brownstone, D. and Small K. A. (2005) Valuing Time and Reliability: Assessing the Evidence from Road Pricing Demonstrations. Transportation Research Part A 39. Available online at http://www.its.uci.edu/its/publications/papers/JOURNALS/sdarticle-1.pdf.

Bureau of Labor Statistics (2010) Consumer Price Index - All Urban Consumers. Available Online at http://data.bls.gov/PDQ/servlet/SurveyOutputServlet.

Cambridge Systematics (2000) Surface Transportation Efficiency Analysis Model (STEAM 2.0) User Manual. Submitted to the Federal Highway Administration. Available online at: http://www.fhwa.dot.gov/steam/steammanual20.pdf.

Capital Area Metropolitan Planning Organization (2009) Traffic Counts: TxDOT Annual \& CTRMA for 2008 - Austin-Round Rock MSA. Accessed Online at: http://www.campotexas.org/pdfs/Traffic\%20Counts\%202008\%20for\%20website.pdf. 
Carlson, Thomas, Robert Dulla, J. Kuzmyak, and Christopher Porter (2005) COMMUTER Model v2.0 User Manual. Sierra Research and Cambridge Systematics. Prepared for the EPA. Available online at: http://www.epa.gov/OMS/stateresources/policy/transp/commuter/420b05017.pdf.

Davis, S. and S. Diegel (2007) Transportation Energy Data Book: Edition 26. Center for Transportation Analysis: Energy Division, Oak Ridge National Laboratory. Available online at: http://cta.ornl.gov/data/index.shtml.

DeCorla-Souza, Patrick (1999) IMPACTS Spreadsheet Software Documentation. Federal Highway Administration.

Environmental Protection Agency (2010) Light-Duty Automotive Technology and Fuel Economy Trends: 1975 Through 2007 - Executive Summary. Available online at: http://www.epa.gov/oms/cert/mpg/fetrends/420s07001.htm\#pagetop

Federal Highway Administration (2005) Highway Economic Requirements System - State Version - Technical Report. U.S. Department of Transportation.

Federal Highway Administration (2007) Asset Management - Evaluation and Economic Investment. Available online at: http://www.fhwa.dot.gov/infrastructure/asstmgmt/primer03.cfm.

Federal Highway Administration (2009) Traffic Volume Trends December 2009. Available online at: http://www.fhwa.dot.gov/ohim/tvtw/09dectvt/09dectvt.pdf.

Federal Highway Administration (2010) Safe, Flexible, Efficient Transportation Equity Act: A Legacy for Users. Available online at: http://www.fhwa.dot.gov/safetealu/factsheets/natlregl.htm.

Government Accountability Office (2008) Surface Transportation Restructured Federal Approach Needed for More Focused Performance-Based and Sustainable Programs. Available online at: http://www.gao.gov/new.items/d08400.pdf.

Health Effects Institute (2007) Mobile-Source Air Toxics: A Critical Review of the Literature on Exposure and Health Effects. Cambridge, MA. Available online at: http://pubs.healtheffects.org/getfile.php? $\mathrm{u}=384$.

Jackson, Pamela (2006) The Federal Excise Tax on Gasoline and the Highway Trust Fund: A Short History. Congressional Research Service. Available online at: http://ncseonline.org/NLE/CRSreports/06May/RL30304.pdf.

Kockelman, Fagnant, Xie and Waller (2010) Toolkit for Anticipating and Evaluating Impacts of Roadway Expansion and Tolling Projects. Research Report on Project \#0-6235 to the Texas DOT. Center for Transportation Research, University of Texas at Austin. 
Lemp, J. and K. Kockelman. (2009). “Anticipating welfare impacts via travel demand forecasting models: Comparison of aggregate and activity-based approaches for the Austin, Texas region." Transportation Research Record, 2133, 11-22.

M. Maibach, et al. (2008) Handbook on Estimation of External Cost in the Transport Sector, CE Delft (www.ce.nl); at http://ec.europa.eu/transport/sustainable/doc/2008 costs handbook.pdf.

Margiotta, Richard. (2009) Cambridge Systematics. Private communication by e-mail exchange. October 7, 2009.

McCubbin, D. and M. Delucchi (1996) Health Effects of Motor Vehicle Air Pollution. Institute for Transportation Studies, University of California, Davis.

National Safety Council (2010) Estimating the Costs of Unintentional Injuries. Available Online at

http://www.nsc.org/news resources/injury and death statistics/Pages/EstimatingtheCostsofUni ntentionalInjuries.aspx.

Newnan, Donald G and Jerome P. Lavelle (1998) Essentials of Engineering Economic Analysis. Engineering Press: Austin, TX.

System Metrics Group, Inc. and Cambridge Systematics, Inc (2009) California Life-Cycle Benefit/Cost Analysis Model. User's Guide Version 4.0. Available online at: http://www.dot.ca.gov/hq/tpp/offices/ote/benefit files/CalBC_User_Guide_v8.pdf.

Texas Department of Transportation (2009) Rural and Urban Crashes and Injuries by Severity 2008. Available Online at ftp://ftp.dot.state.tx.us/pub/txdotinfo/trf/crash statistics/2008/2008 9.pdf

U.S. Census Bureau (2000) Historical National Population Estimates. Available online at: http://www.census.gov/popest/archives/1990s/popclockest.txt.

U.S. Census Bureau (2009) Annual Estimates of the Population of the United States, Regions, States and Puerto Rico: April 1, 2000 to July 1, 2009. Available online at: http://www.census.gov/popest/national/national.html.

Victoria Transport Policy Institute (2009) Transportation Cost and Benefit Analysis Techniques, Estimates and Implications. Second Edition. Available online at: http://www.vtpi.org/tca/.

West, B.H., R.N. McGill, J.W. Hodgson, S.S. Sluder, and D.E. Smith (1997) Development and Verification of Light-Duty Modal Emissions and Fuel Consumption Values for Traffic Models, FHWA Report (in press), Washington, DC, April 1997, and additional project data, April 1998. (Additional resources: www.fhwa-tsis.com) 
Xie, Chi, Kara Kockelman, and Travis Waller (2010) A Maximum Entropy Method for Subnetwork Origin-Destination Trip Matrix Estimation. Transportation Research Record. Available online at: http://www.ce.utexas.edu/prof/kockelman/. 